\title{
COLONY INCOMPATIBILITY AMONG STRAINS OF ESCHERICHIA COLI ISOLATED DURING AN OUTBREAK OF GASTROENTERITIS IN ONE WARD
}

\author{
K. A. Bettelheim \\ National Health Institute, PO Box 7126, Wellington South, New Zealand
}

SEVERAL explanations have been proposed to account for the Dienes phenomenon that occurs between some strains of Proteus (Dienes, 1946). Senior (1977) suggested that proticines played a major role in the phenomenon but that not all the results could be explained in this way.

The term "colony incompatibility" was coined by Bettelheim and Carlile (1976) to include the Dienes phenomenon of Proteus as well as similar interactions among other motile bacteria. Recent studies of salmonellas (Bettelheim, 1978a and $b$ ) have shown that neither serotype nor bacteriocine production nor phage type correlate with incompatibility. Although colony incompatibility is still unexplained, it was decided to examine its possible ecological significance in a hospital environment.

\section{MATERIALS AND METHODS}

Subjects. Babies from one ward in an Auckland hospital were randomly selected during an outbreak of gastroenteritis for which a viral aetiology was subsequently demonstrated.

Specimens and cultural methods. Rectal swabs from babies were sent to Wellington where tests for the presence of enteropathogenic Escherichia coli were carried out. Swabs were spread on MacConkey agar and $10 E$. coli-like colonies were selected. They were identified as E. coli by the method of Cooke, Ewins and Shooter (1969).

Serological methods. Strains of E. coli were O serotyped as described by Meekin, Bettelheim and Bacon (1979) and motile strains were $\mathrm{H}$ serotyped by the methods of Chandler and Bettelheim (1974). Non-motile strains could not be used in this study.

Incompatibility studies. All strains were passed repeatedly through Craigie-type tubes containing semisolid agar. When fully motile as determined by microscopic observation, they were transferred to Dorset egg slopes and stored at room temperature in the dark. Strains of Salmonella stored in this way maintain their full motility (Bettelheim, 1978a). In the course of this study the strains of $E$. coli similarly maintained full motility.

Each strain studied for incompatibility was tested against each other strain on semisolid nutrient agar, in which the agar concentration was $0.35 \%$. The plates were examined after incubation for 4 days at $37^{\circ} \mathrm{C}$. Degrees of incompatibility were scored as described by Bettelheim (1978a) (table I) and although there is a certain amount of subjectivity in the scoring, the results are reasonably reproducible. Repeated tests on the same pair of strains usually showed differences of only one score point. Nevertheless all results described here are replicates of several tests.

\section{RESULTS AND DISCUSSION}

The results of serotyping the strains and the number of strains studied are shown in table II. When possible, more than one strain representing each serotype was chosen from each baby. The incompatibility results are shown in table III. For each strain, the total of the incompatibility scores against all the other strains was used as the "incompatibility index".

It was unfortunate that some of the serotypes studied belonged to $O$ groups that were not

Received 10 July 1979; accepted 3 Dec. 1979. 


\section{TABLE I}

System of scoring incompatibility reactions

\begin{tabular}{|c|c|}
\hline Score & Observation \\
\hline 0 & Total or partial merging of swarms \\
\hline 1 & "Bunching"*, no clear zone between swarms \\
\hline 2 & $\begin{array}{l}\text { "Bunching", clear zone less than } 1 \mathrm{~mm} \\
\text { between swarms }\end{array}$ \\
\hline 3 & $\begin{array}{l}\text { "Bunching", clear zone } 1-10 \mathrm{~mm} \text { between } \\
\text { swarms }\end{array}$ \\
\hline 4 & $\begin{array}{l}\text { "Bunching", clear zone greater than } \\
10 \mathrm{~mm} \text { between swarms }\end{array}$ \\
\hline
\end{tabular}

* The term "bunching" is used to describe the increased density of organisms near the demarcation zone between incompatible strains.

TABLE II

Serotypes of Escherichia coli isolated from babies suffering from gastroenteritis

\begin{tabular}{|c|c|c|c|c|}
\hline \multirow[b]{2}{*}{ Baby } & \multirow{2}{*}{$\begin{array}{l}E . \text { coli } \\
\text { serotypes } \\
\text { found }\end{array}$} & \multicolumn{2}{|c|}{ Number of colonies } & \multirow[b]{2}{*}{$\begin{array}{c}\text { Number not } \\
\text { E. coli }\end{array}$} \\
\hline & & found & $\begin{array}{c}\text { studied for } \\
\text { incompatibility }\end{array}$ & \\
\hline $\mathbf{A}$ & O1.H7 & 9 & 3 & 0 \\
\hline B & Ont.H2 & 1 & 1 & 8 \\
\hline & Ont.H19 & 1 & $i$ & \\
\hline C & Ont.H11 & 1 & $i$ & 9 \\
\hline D & O23.H16 & 3 & 3 & 7 \\
\hline $\mathrm{E}$ & OX8.H15 & 6 & 3 & 4 \\
\hline $\mathbf{F}$ & Ont.H4 & 10 & 4 & 0 \\
\hline$G$ & $\mathrm{O} 2 . \mathrm{H} 4$ & 3 & 2 & 1 \\
\hline & O15.H18 & 4 & 1 & \\
\hline & Ont.H14 & 1 & 1 & \\
\hline & $\mathrm{O}$ rough. $\mathrm{H} 4$ & 1 & $i$ & \\
\hline $\mathbf{H}$ & Ont.H10 & 3 & 2 & 7 \\
\hline
\end{tabular}

Ont $=$ not typable with 1630 sera; $O X 8=$ a serotype that has not yet been given an international number (Ørskov, personal communication).

typable with any accepted $O$ antisera. However, studies now in progress in New Zealand suggest that there are indigenous serogroups that have not been found in other parts of the world.

The results shown in table III were unexpected. On the basis of the studies on salmonellas it was thought that strains of the same serotype from the same source would be compatible and show similar compatibility patterns with other strains. However, this was not the case with $E$. coli. Only the four strains from patient $\mathrm{F}$, which were of serotype Ont. 44 , were fully compatible and behaved mainly in similar ways with the other strains. The strains from patient A were strongly incompatible with each other although they were all of serotype O1.H7; they generally behaved similarly with other strains. The serogroup $\mathrm{O} 1 . \mathrm{H} 7$, is exceedingly common, having been isolated from a variety of sources, human and animal, in health and disease, in many parts of the world (Bettelheim, 1978c). It is also often associated with the $\mathrm{K} 1$ antigen, and $E$. coli carrying this antigen is commonly associated with neonatal meningitis. If strains of this serogroup are generally incompatible with other $E$. coli and even with each other, this may explain why serogroup $\mathrm{O} 1 . \mathrm{H} 7$ is so widespread and possibly able to replace other serotypes in a given habitat. 


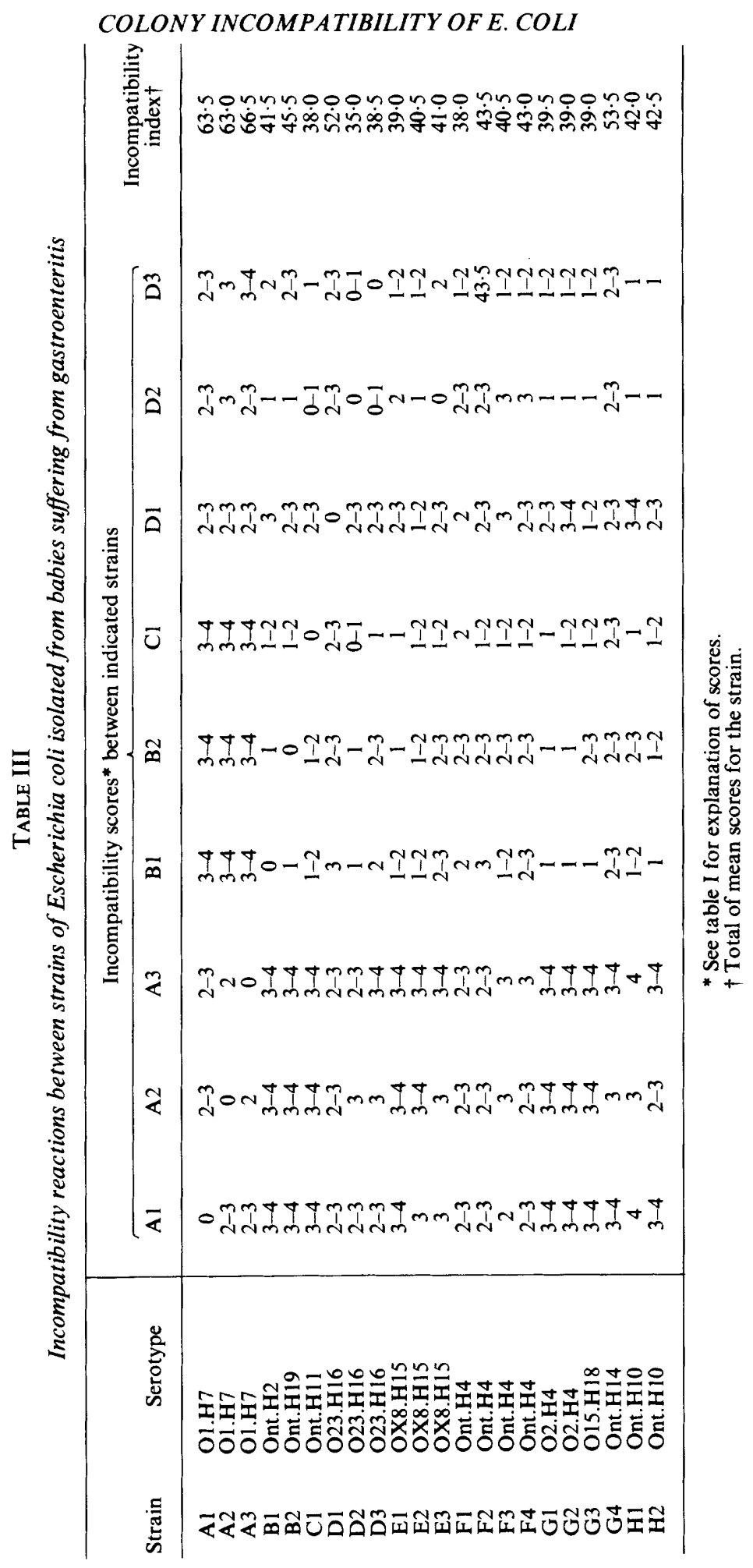




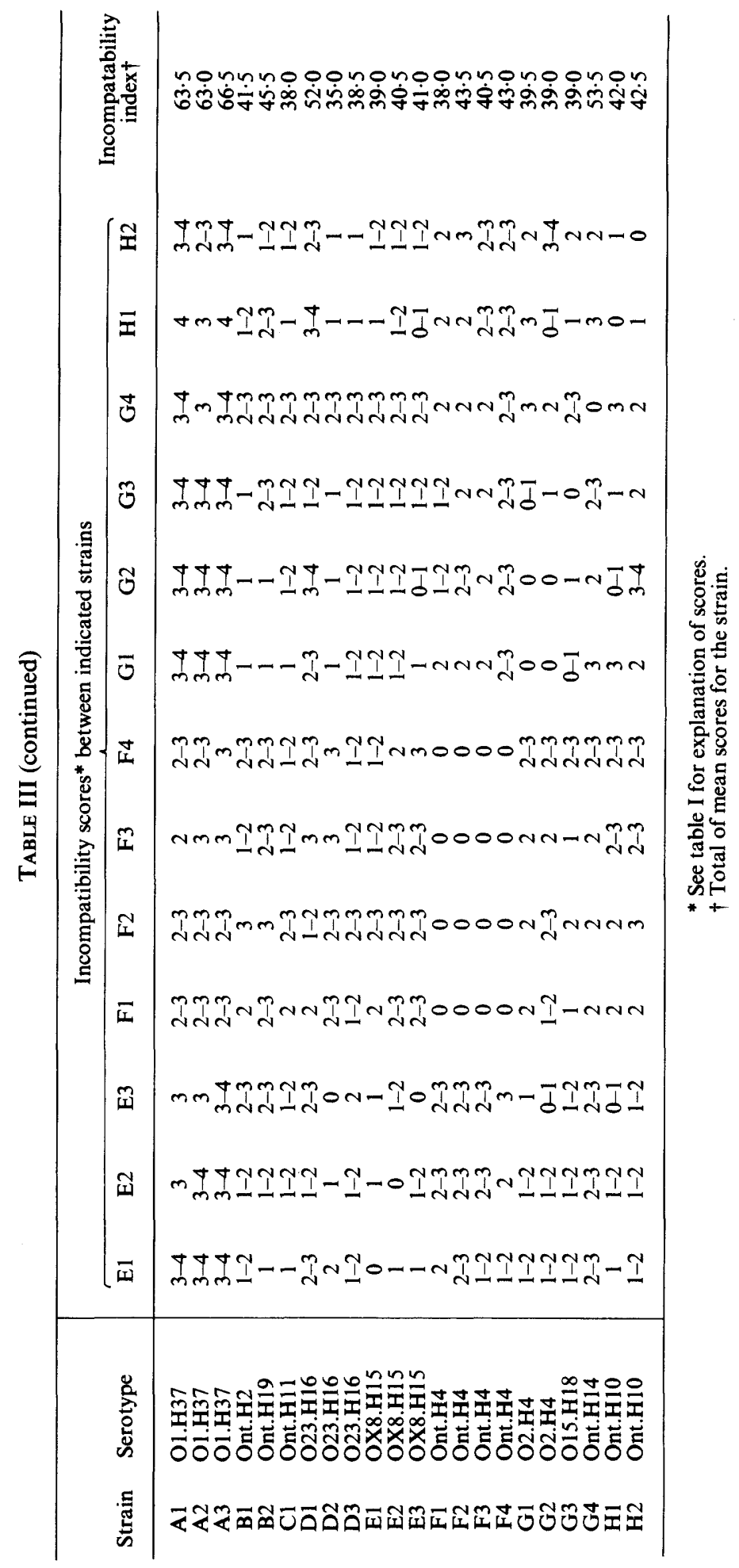




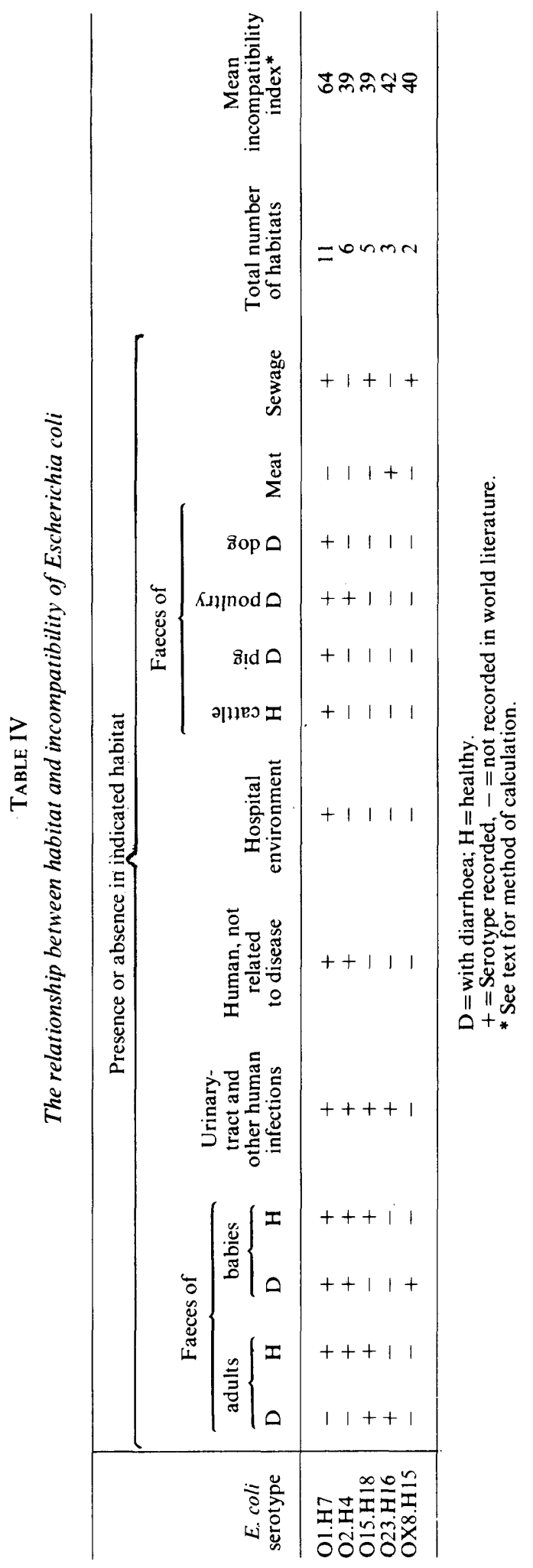


Strains of the other fully typable serogroups are not as widespread in the environment and this may be reflected in their far greater compatibility with each other. On the basis of the results obtained, all the incompatibilities of the five fully identified serotypes were added and the mean per serogroup was calculated. This arbitrary figure was taken as the "mean incompatibility index". It was highest for serotype $\mathrm{O} 1 . \mathrm{H} 7$ which is present in most of the habitats described in the world literature (Bettelheim, 1978c, and over 500 papers published since 1944). The results are shown in table IV.

Strong incompatibility reactions with other serotypes may give some $E$. coli serotypes a greater selective advantage in a given habitat. Further studies on the mechanisms of incompatibility and on a larger variety of strains may confirm these suggestions.

\section{SUMMARY}

Strains of Escherichia coli, isolated during an outbreak of infantile gastroenteritis in one ward, were serotyped and tested for incompatibility against each other on semisolid agar. Serotypes commonly isolated in various parts of the world from various habitats showed a greater incompatibility than more rarely isolated serotypes, suggesting that the former may have a selective advantage and be more able to displace other serotypes in a given habitat.

Published with the authority of the Director-General of Health, Department of Health, Wellington, New Zealand.

\section{REFERENCES}

BetTelheim, K. A. 1978a. Colony incompatibility among New Zealand isolates of Salmonella typhimurium. J. gen. Microbiol., 107, 249.

BetTELHEIM, K. A. 1978b. Colony incompatibility among strains of Salmonella. In Microbial ecology, edited by M. W. Loutit and J. A. R. Miles. Springer-Verlag: Berlin, p. 255.

Bettelheim, K. A. 1978c. The sources of 'OH' serotypes of Escherichia coli. J. Hyg.,Camb., $80,83$.

Bettelheim, K. A. and Carlile, M. J. 1976. Colony incompatibility in bacteria. Nature, Lond., $264,757$.

Chander, M. E. AND Bettelheim, K. A. 1974. A rapid method of identifying Escherichia coli H antigens. Zentbl. Bakt. ParasitKde, I. Abt. Orig., 229, 74.

COOKE, E. M, EwINs, S. AND SHOOTER, R. A. 1969. Changing faecal population of Escherichia coli in hospital medical patients. Br. med. J., 4, 593.

DiENES, L. 1946. Reproductive processes in proteus cultures. Proc. Soc. exp. Biol. Med., 63, 265.

Meekin, G. E., Bettelheim, K. A. And Bacon, D. F. 1979. Serotypes of antibiotic resistant Escherichia coli isolated from the sewage of Palmerstone North (New Zealand). J. Hyg., Camb., 82, 443.

SENIOR, B. W. 1977. The Dienes phenomenon: identification of the determinants of compatibility. J. gen. Microbiol., 102, 235. 